\title{
ETHzürich
}

ETH Library

Rapid analysis of fragrance allergens by dielectric barrier discharge ionization mass spectrometry

Journal Article

Author(s):

Liu, Qinlei (1); Zenobi, Renato (1)

Publication date:

2021

Permanent link:

https://doi.org/10.3929/ethz-b-000467737

Rights / license:

$\underline{\text { In Copyright - Non-Commercial Use Permitted }}$

Originally published in:

Rapid Communications in Mass Spectrometry 35(6), https://doi.org/10.1002/rcm.9021 


\section{Rapid Analysis of Fragrance Allergens by Dielectric Barrier Discharge Ionization Mass Spectrometry}

Qinlei Liu, Renato Zenobi

Department of Chemistry and Applied Biosciences, ETH Zurich, CH-8093 Zurich, Switzerland

Correspondence

R. Zenobi, Department of Chemistry and Applied Biosciences, ETH Zurich, CH-8093 Zurich, Switzerland. E-mail: zenobi@org.chem.ethz.ch

RATIONALE: Fragrances are organic compounds with pleasant odors that are widely used in every aspect of our daily life; some fragrance ingredients can cause allergic reactions. Hence, the qualitative and quantitative analysis of fragrances allergens can prevent consumers getting into contact with fragrance allergens. In this study, we evaluated the ability of a dielectric barrier discharge ionization (DBDI) source for analyzing allergens that occur in fragrances.

METHODS: A home-built liquid infusion device was used for evaporating the liquid samples. An active capillary plasma ionization source, which is based on a dielectric barrier discharge, was used to ionize the analytes. Mass spectra were acquired in positive ion mode with an LTQ Orbitrap mass spectrometer.

RESULTS: Seven typical fragrance allergens were analyzed in this study. The limits of detections (LODs) were as low as $0.0001 \mathrm{ppm}$ and a linear dynamic range of 2-3 orders of magnitude was achieved. Allergens in five different perfume products were successfully analyzed and quantified by this method, with analysis times of less than 1 min of each sample.

CONCLUSIONS: This work introduces a DBDI-MS-based analytical method for detecting and quantifying fragrance allergens. Since DBDI has the advantages of high sensitivity, simple operation and fast analysis time, it is very suitable for the rapid analysis of trace allergens in fragrances, and could easily be used for quality control of consumer products in the cosmetics market. 


\section{Introduction}

Fragrances are organic compounds with pleasant or sweet odors either obtained from natural sources or produced synthetically, which is often cheaper and saves resources. Natural fragrances contain ingredients of natural origin, for example, essential oils, resins and animal secretions. Synthetic fragrances are compounds that may or may not exist in nature. ${ }^{[1]}$ Nowadays, there are more than 3000 chemical substances being utilized as fragrances in every aspect of our daily life, for example in perfumes, deodorants, aftershave products, shampoos, conditioners, laundry products, cleaning products and so on. ${ }^{[2]}$

Although fragrances predominantly produce pleasant scents and help to mask unpleasant odors, some fragrance ingredients can cause allergic reactions. The Scientific Committee on Cosmetic Products and Non-Food Products Intended for Consumers (SCCNFP) identified 26 compounds that may lead to allergies in human beings; these are termed fragrance allergens. ${ }^{[2]}$ The legal situation of these fragrance allergens in cosmetic products is that if the concentration of the 26 fragrance allergens exceed $10 \mathrm{ppm}$ (leave-on cosmetic products) / $100 \mathrm{ppm}$ (rinse-off cosmetic products), they must be labeled on cosmetic products, alerting consumers to avoid the risk of sensitization that may occur. ${ }^{[2]}$ However, it is not easy to detect allergens in fragrances that cause allergic reactions, because fragrance ingredients are complex, and the composition ratios of different brands are different. ${ }^{[3]}$ Many ingredients are commercial secrets and are not disclosed. Therefore, it is difficult for allergy sufferers to determine which ingredients in fragrances they are allergic to, and it is also difficult to determine the specific allergic reactions caused by different fragrances. ${ }^{[4]}$ Hence, the qualitative and quantitative analysis of compounds in fragrances, especially of some fragrances allergens, can prevent consumers getting into contact with fragrance allergens.

Currently, compounds of fragrances are mainly analyzed by gas chromatography (GC) or liquid chromatography (LC) separation before being subjected to mass spectrometric analysis 
using ionized by electron ionization (EI), electrospray (ESI) or atmosphere pressure chemical ionization (APCI). ${ }^{[5-8]}$ However, EI usually produces a lot of fragment ions. The molecular ion is often absent or of very low intensity, which renders quantification of compounds with nonspecific fragmentation more difficult and less sensitive. ${ }^{[9]}$ ESI is not applicable for studying non-polar molecules. APCI has a limited application range and is mainly used for the analysis of weakly polar compounds, and is usually more prone to matrix effects compared to EI. ${ }^{[10]}$ Dielectric barrier discharge ionization (DBDI) has been developed a lot in recent years, ${ }^{[11,12]}$ and features a small size, simple structure, low cost, high efficiency, good reproducibility, and is easy to operate. Since DBDI can ionize polar, mid-polarity, as well as non-polar compounds, ${ }^{[13]}$ its application to fragrances analysis could make an interesting contribution. In this work, the use of an active capillary plasma ionization source (based on DBDI), which was developed in our research group,${ }^{[14,15]}$ was explored for quantitative determination of fragrance allergens. Since DBDI is less affected by matrix effects and ion suppression than ESI and $\mathrm{APCI},{ }^{[16,17]}$ it should allow the analysis of several fragrance allergens simultaneously without any prior chromatographic separation. In this way, the analysis time can be greatly reduced while the sensitivity is still satisfactory. This will allow to greatly shorten working time and improve work efficiency when there are a large number of perfume samples that need to be screened.

\section{Experimental section}

\section{Chemicals}

Benzyl benzoate, coumarin, eugenol, citral, linalool, citronellol, limonene, methanol (99.9\%) were purchased from Sigma-Aldrich Chemie GmbH (Buchs, Switzerland). The structures of the measured compounds are shown in Figure 1. 


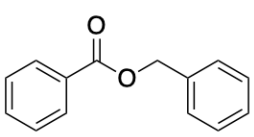

Benzyl benzoate $M W=212.1$

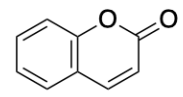

Coumarin $\mathrm{MW}=146.0$

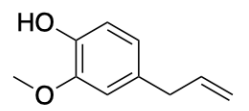

Eugenol

$\mathrm{MW}=164.0$

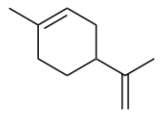

Limonene $\mathrm{MW}=136.1$
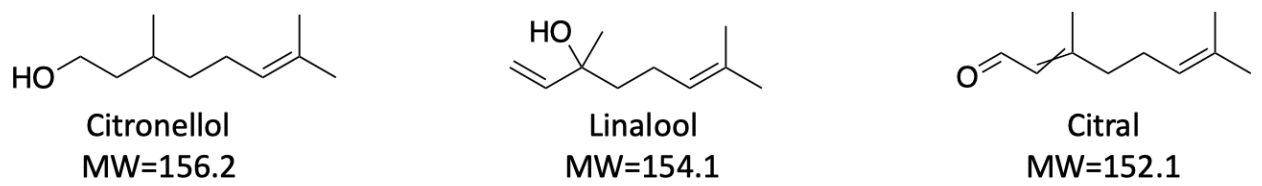

Figure 1. Fragrance allergens investigated in this work.

\section{Sample preparation}

Individual fragrance allergen stock solutions were prepared at a concentration of $1000 \mathrm{ppm}$ in $\mathrm{MeOH}$, and stored at $4{ }^{\circ} \mathrm{C}$. A mixture of the 7 fragrances allergens (benzyl benzoate, coumarin, eugenol, citral, linalool, citronellol and limonene) was prepared at a concentration of $100 \mathrm{ppm}$ in $\mathrm{MeOH}$, and stored at $4{ }^{\circ} \mathrm{C}$. Diluted solutions used for the whole experiment were prepared in $\mathrm{MeOH}$ and stored at a temperature of $4{ }^{\circ} \mathrm{C}$. The commercial perfume products were diluted 100 times in $\mathrm{MeOH}$ and were stored at a temperature of $4{ }^{\circ} \mathrm{C}$.

\section{Sample Introduction System}

A home-built liquid infusion device was used for evaporating the liquid samples. ${ }^{[11,18]}$ In short, as shown in Figure 2, a pressurized vial ( 1 bar overpressure) was connected to a hollow heating cartridge $\left(200^{\circ} \mathrm{C}, 1.4 \mathrm{~L} / \mathrm{min}_{2}\right)$ through a fused silica capillary (40 $\mu \mathrm{m} \mathrm{ID,} 30 \mathrm{~cm}$ length). The sample flowed into the heating cartridge and was evaporated. The flow of the sample and the resulting gas-phase concentration of the analyte was calculated by Poiseuille's law as reported by Wolf et al. ${ }^{[19]}$ A humidified gas stream $\left(\mathrm{N}_{2}, 1.3 \mathrm{~L} / \mathrm{min}\right)$ which can support the formation of protonated molecules and decrease in-source fragmentation ${ }^{[20]}$ was used to transport the evaporated sample to the plasma source. The outlet of the heating cartridge was connected to 
the DBDI source via a T-piece, and the excess gas left through the exhaust.

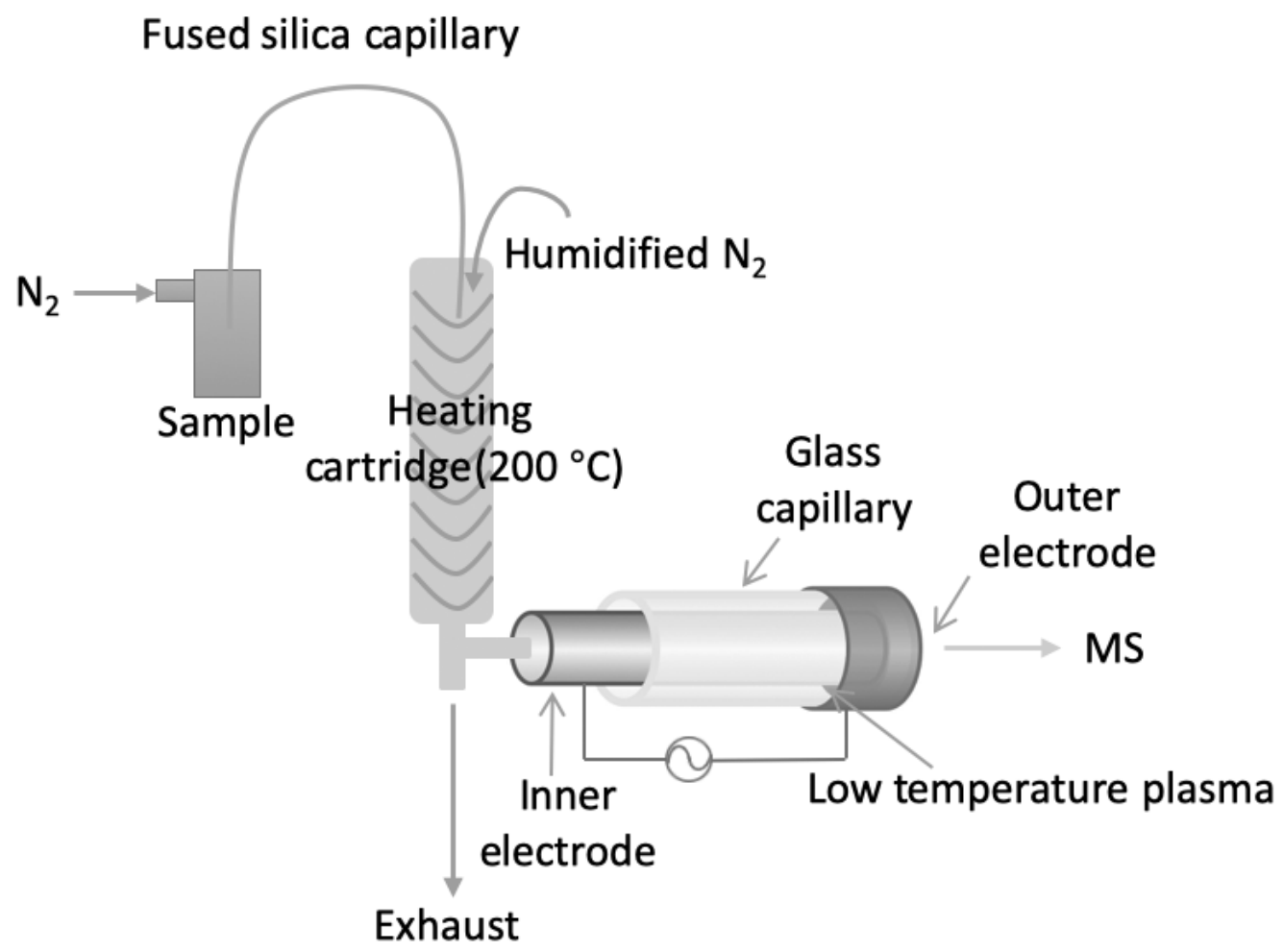

Figure 2. Schematic of the sample introduction system in this study.

\section{Ionization source}

An active capillary plasma ionization source, which is based on a dielectric barrier discharge, was used to ionize the analytes in this work. ${ }^{[11,18]}$ As shown in Figure 2, the DBDI has two electrodes, an inner electrode (ground, stainless steel, ID: $0.6 \mathrm{~mm}$ and OD: $1.0 \mathrm{~mm}$ ) and an outer electrode (high voltage, copper, ID: $1.55 \mathrm{~mm}$, surrounding the glass capillary). They are separated by an insulating layer, here a glass capillary, which serves as the dielectric barrier. After applying a high $\mathrm{AC}$ voltage $(3.0 \mathrm{kVpp}, 47 \mathrm{kHz})$ to the outer electrode, a plasma is ignited inside the capillary. The DBDI source was connected directly to the inlet capillary of the mass spectrometer to achieve an almost $100 \%$ transmission efficiency of the ions formed.

\section{Mass Spectrometry}

Mass spectra were acquired in positive ion mode, with an LTQ Orbitrap mass spectrometer 
(Thermo Fischer Scientific, San Jose, U.S.A.), in fullscan mode at a resolution of 30,000 FWHM (at m/z 400) with a mass tolerance specified to be $<10 \mathrm{ppm}$. The mass-to-charge range was set to $50-250$, capillary voltage is $50 \mathrm{~V}$, tube lens voltage is $120 \mathrm{~V}$, capillary temperature is $195^{\circ} \mathrm{C}$. Mass spectra were acquired using 3 microscans and a maximum injection time of $100 \mathrm{~ms}$.

\section{Calibration curves}

The stock solutions of 7 fragrances allergens (benzyl benzoate, coumarin, eugenol, citral, linalool, citronellol and limonene) were diluted to $0.01 \mathrm{ppb}, 0.1 \mathrm{ppb}, 1 \mathrm{ppb}, 10 \mathrm{ppb}, 100 \mathrm{ppb}$, $1 \mathrm{ppm}, 10 \mathrm{ppm}$ in $\mathrm{MeOH}$ separately and measured by DBDI-MS. We first plotted the results to check in which concentrations there is a linear relationship. Further calibration points in this range were then chosen to generate a new calibration curve with a linearity range of 0.99 . In the end, 5 calibration points were used for each calibration curve.

By measuring samples with decreasing concentrations and using a signal-to-noise ratio $(\mathrm{S} / \mathrm{N})$ criterion of 3, the limits of detection (LODs) were evaluated. The limits of quantification (LOQs) were calculated from the calibration curves.

\section{Standard addition method}

Since the ingredients list of "Bright crystal" contains linalool, citronellol and limonene, standard addition was also performed for linalool, citronellol and limonene. Several $15 \mathrm{~mL}$ tubes were each filled with $100 \mu \mathrm{L}$ each of the "Bright crystal". Linalool (10 ppm) was added in different quantities, $0,1,2,3,4$ and $5 \mathrm{~mL}$. The solutions in the tubes were then diluted to 10 $\mathrm{mL}$ and mixed well. The procedure for citronellol and limonene were the same as that for limonene. 


\section{Results and Discussion}

Optimization of the temperature of the heating cartridge, sample volume, DBDI voltage, flow rate of humidified $\mathrm{N}_{2}$ and flow rate of $\mathrm{N}_{2}$ was performed and is given in the supporting information (Figure S1). Benzyl benzoate, coumarin, eugenol, citral, linalool, citronellol, and limonene are typical fragrance allergens, and widely used in the fragrance industry (see Figure 1). The DBDI source can easily ionize these compounds. Mixtures of fragrance allergen were also measured in this study. The mass spectra of 7 individual fragrance allergens and of the mixture are shown in Figure S2 and Figure 3a. It can be seen that in addition to the target compounds, there are many small peaks in the spectrum (see Figure 3a). In order to get information about their origin, we compared the mass spectra of the mixture of 7 fragrances (Figure 3a), citronellol (Figure 3b), the background (Figure 3c) and Figure S3 (showing an overlay of Figures 3b and 3c) in the same mass range. We found that most of the peaks that occur in the mass spectra of the compounds also show up in the background spectrum, and that they do not affect detection of the target compounds. Most of the fragrance allergens investigated in this work were detected as protonated molecules, except limonene (the observed ion was $\left[\mathrm{M}+\mathrm{H}+\mathrm{H}_{2} \mathrm{O}\right]^{+}$) and linalool (the observed ion was $\left[\mathrm{M}+\mathrm{H}-\mathrm{H}_{2} \mathrm{O}\right]^{+}$). Their identification was based on accurate mass, and the observed $\mathrm{m} / \mathrm{z}$ values of the product ions, the theoretical $\mathrm{m} / \mathrm{z}$ values of the product ions and the mass error are listed in Table 1. The observed mass of eugenol, citral, citronellol, limonene show higher mass errors than others, which is an MS calibration issue. Since a $10 \mathrm{ppm}$ mass tolerance was used for MS signal integration, even these higher mass errors are acceptable. 
(A) a mixture of 7 fragrance allergens

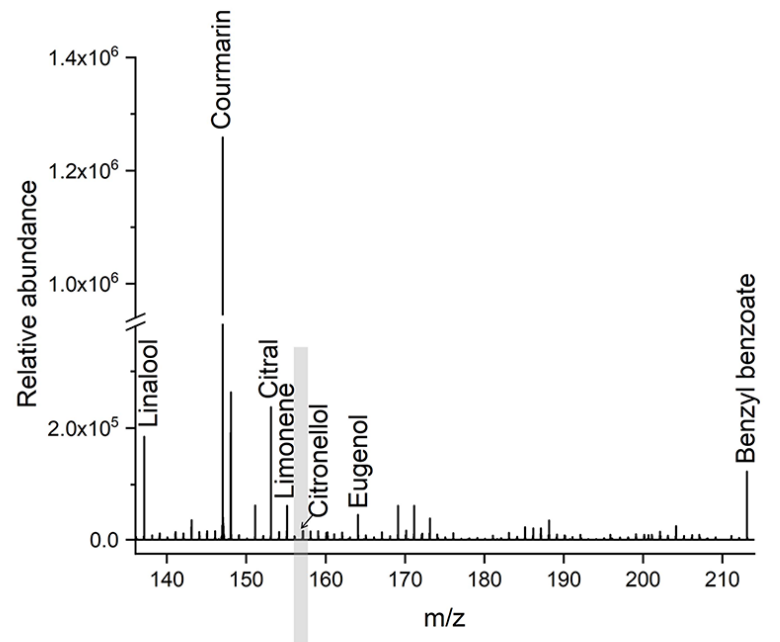

(B) citronellol alone

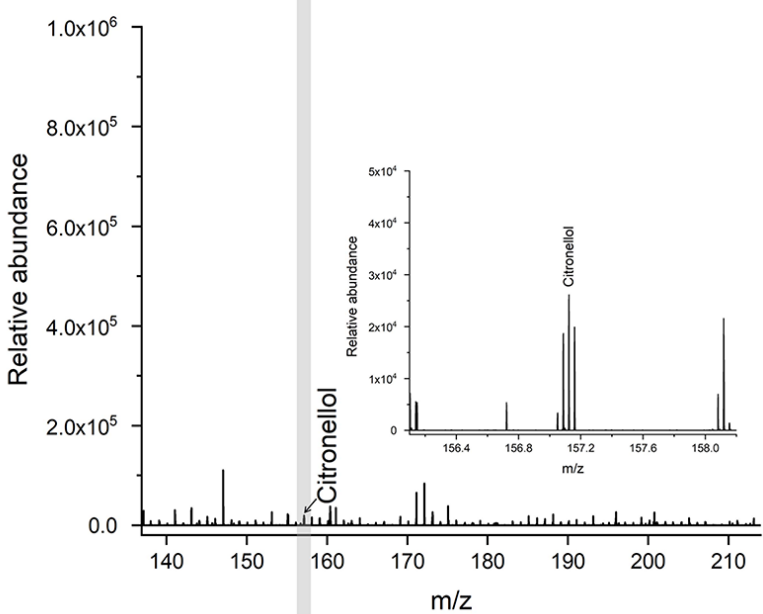

(C) background

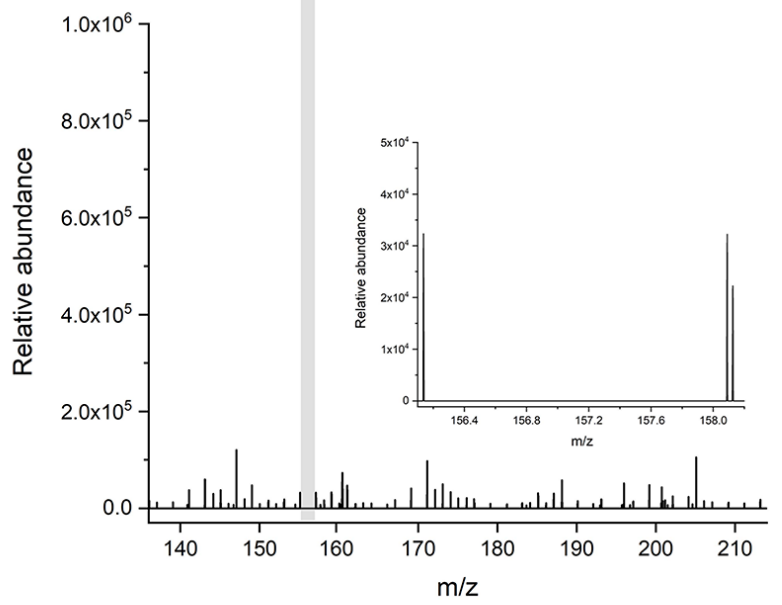

Figure 3. High-resolution mass spectrum of (A) a mixture of 7 fragrance allergens, (B) citronellol and (C) background (at a solution concentration of $1 \mathrm{ppm}$ ). The to the right of coumarin in (A) is from phthalic anhydride $(\mathrm{m} / \mathrm{z}=148.1)$, a plasticizer and a commonly observed background ion in DBDI. 
Table 1. Measured $\mathrm{m} / \mathrm{z}$ for the Ions Produced from the Different Fragrance Allergens

\begin{tabular}{ccccc}
\hline Analyte & Ions produced & $\begin{array}{c}\text { Observed mass } \\
(\mathbf{m} / \mathbf{z})\end{array}$ & $\begin{array}{c}\text { Theoretical mass } \\
(\mathbf{m} / \mathbf{z})\end{array}$ & $\begin{array}{c}\text { Mass error } \\
(\mathbf{p p m})\end{array}$ \\
\hline $\begin{array}{c}\text { Benzyl } \\
\text { benzoate }\end{array}$ & {$[\mathrm{M}+\mathrm{H}]^{+}$} & 213.0914 & 213.0916 & 0.9 \\
\hline Coumarin & {$[\mathrm{M}+\mathrm{H}]^{+}$} & 147.0447 & 147.0446 & 0.7 \\
\hline Eugenol & {$[\mathrm{M}+\mathrm{H}]^{+}$} & 165.0924 & 165.0916 & 4.8 \\
\hline Citral & {$[\mathrm{M}+\mathrm{H}]^{+}$} & 153.1289 & 153.1279 & 6.5 \\
\hline Linalool & {$\left[\mathrm{M}+\mathrm{H}-\mathrm{H}_{2} \mathrm{O}\right]^{+}$} & 137.1338 & 137.1330 & 0.7 \\
\hline Citronellol & {$\left[\mathrm{M}+\mathrm{H}^{+}\right.$} & 157.1603 & 157.1592 & 6.9 \\
\hline Limonene & {$\left[\mathrm{M}+\mathrm{H}+\mathrm{H}_{2} \mathrm{O}\right]^{+}$} & 155.1443 & 155.1436 & 4.5 \\
\hline
\end{tabular}

Calibration curves for the individual samples and for the compounds in the mixtures are reported in Figure 4. The direct DBDI approach showed a remarkable sensitivity for coumarin, citral and linalool, with experimental LODs of $0.1 \mathrm{ppb}$ (see Table 2). Benzyl benzoate and eugenol showed LODs of $1 \mathrm{ppb}$. Limonene and citronellol showed LODs of $10 \mathrm{ppb}$ and $50 \mathrm{ppb}$, respectively. The linear dynamic range of the method was two to three orders of magnitude. As shown in Figure 4, the slope of the calibration curves for single compounds are systematically somewhat larger than for the same compounds in mixtures, which could be the result some matrix effects due to competition for charge. It is worth noting, however, that the LOD, LOQ and linear dynamic range for the same compound was the same, irrespective of whether it was used in pure form or present in a mixture, which suggests that although some charge competition exists, it is not strong.

Thus, DBDI has a satisfactory linear dynamic range, high accuracy and sensitivity, and can be used for the rapid and sensitive detection of fragrance allergens in perfume products without any sample pretreatment. In addition, when compared with GC-MS, DBDI has 2-4 orders of magnitude lower LOD and 2-3 orders of magnitude lower LOQ when analyzing these 7 fragrance allergens. ${ }^{[21-23]}$ Using DBDI, it only takes a few minutes to analyze a sample, i.e., the analysis time is significantly shorter than for any of the conventional methods to detect and quantify fragrance allergens. ${ }^{[7,8,2,23]}$ 

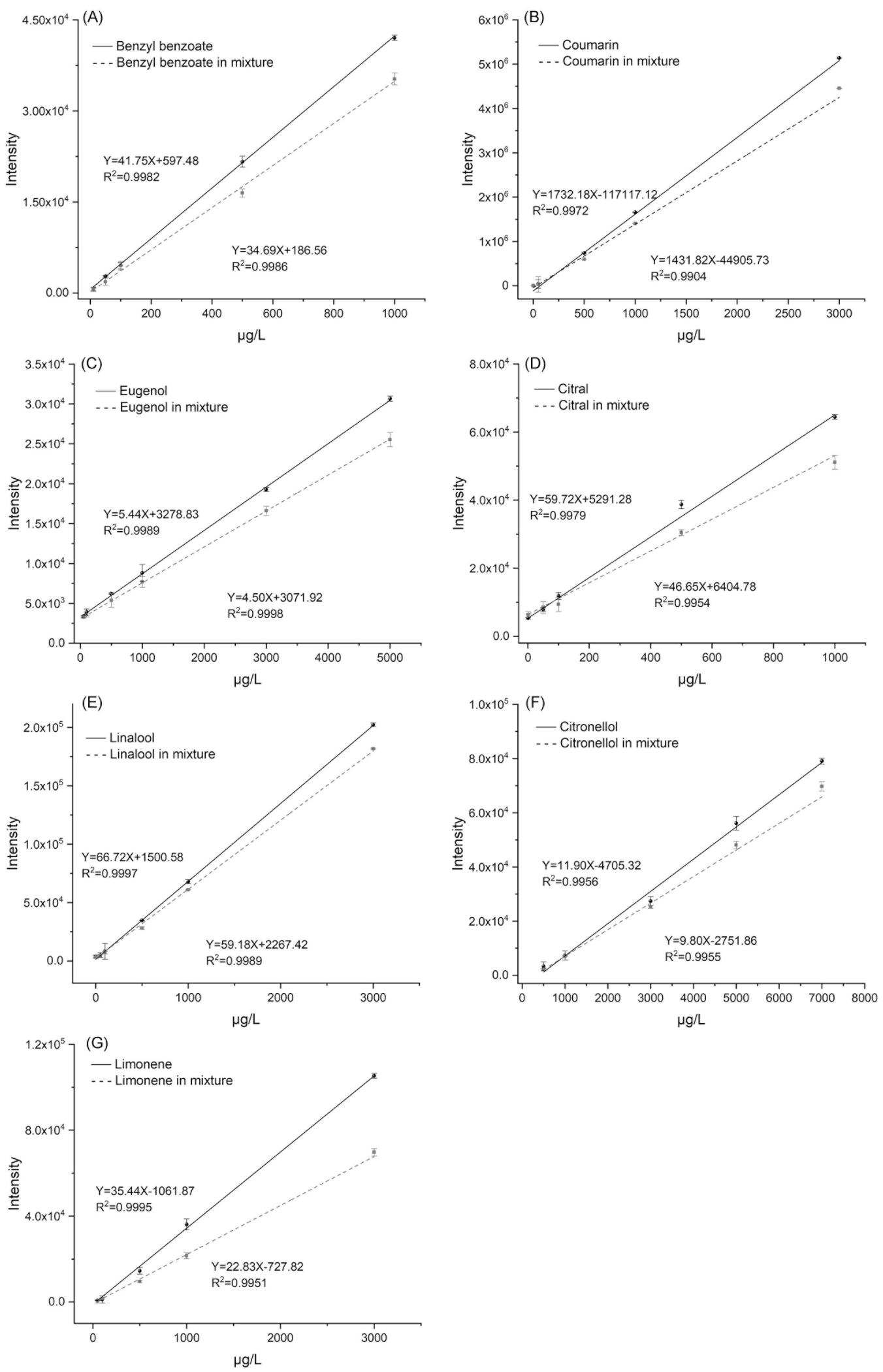

Figure 4. Calibration curves for benzyl benzoate (A), coumarin (B), eugenol (C), citral (D), linalool (E), citronellol $(\mathrm{F})$ and limonene $(\mathrm{G})$. (Black dots represent the individual samples, red triangles represent the mixtures) 
Table 2. The LODs, LOQs and $\mathrm{R}^{2}$ values for detection of 7 fragrance allergens by DBDI-MS and GCMS.

\begin{tabular}{|c|c|c|c|c|c|c|c|c|c|c|c|}
\hline \multirow[b]{2}{*}{ Analyte } & \multicolumn{4}{|c|}{ DBDI-MS } & \multicolumn{4}{|c|}{ DBDI-MS (mixture) } & \multicolumn{3}{|c|}{ GC-MS } \\
\hline & $\begin{array}{l}\text { LOD, } \\
\text { ppm }\end{array}$ & $\begin{array}{l}\text { LOQ, } \\
\text { ppm }\end{array}$ & $\mathbf{R}^{2}$ & $\begin{array}{l}\text { linearity } \\
\text { range, } \\
\text { ppm }\end{array}$ & $\begin{array}{l}\text { LOD, } \\
\text { ppm }\end{array}$ & $\begin{array}{l}\text { LOQ, } \\
\text { ppm }\end{array}$ & $\mathbf{R}^{2}$ & $\begin{array}{l}\text { linearity } \\
\text { range, } \\
\text { ppm }\end{array}$ & $\begin{array}{l}\text { LOD, } \\
\text { ppm }\end{array}$ & $\begin{array}{l}\text { LOQ, } \\
\text { ppm }\end{array}$ & $\mathbf{R}^{2}$ \\
\hline $\begin{array}{l}\text { Benzyl } \\
\text { benzoate }\end{array}$ & 0.001 & 0.01 & 0.9982 & $0.01-1$ & 0.001 & 0.01 & 0.9986 & $0.01-1$ & - & $1^{[22]}$ & $0.9990^{[22]}$ \\
\hline Coumarin & 0.0001 & 0.001 & 0.9972 & $0.001-3$ & 0.0001 & 0.001 & 0.9904 & $0.001-3$ & $1.1^{[23]}$ & $3.8^{[23]}$ & $0.9992^{[23]}$ \\
\hline Eugenol & 0.001 & 0.05 & 0.9989 & $0.050-5$ & 0.001 & 0.05 & 0.9998 & $0.050-5$ & $1.3^{[23]}$ & $4.7^{[23]}$ & $0.9973^{[23]}$ \\
\hline Citronellol & 0.05 & 0.001 & 0.9956 & $0.5-7$ & 0.05 & 0.001 & 0.9955 & $0.5-7$ & $2.1^{[23]}$ & $6.6^{[23]}$ & $0.9980^{[23]}$ \\
\hline Limonene & 0.01 & 0.05 & 0.9995 & $0.05-3$ & 0.01 & 0.05 & 0.9951 & $0.05-3$ & - & $0.5^{[21]}$ & $0.9998^{[21]}$ \\
\hline Linalool & 0.0001 & 0.001 & 0.9997 & $0.001-3$ & 0.0001 & 0.001 & 0.9989 & $0.001-3$ & $1.7^{[23]}$ & $6.4^{[23]}$ & $0.9959^{[23]}$ \\
\hline Citral & 0.0001 & 0.001 & 0.9979 & $0.001-1$ & 0.0001 & 0.001 & 0.9954 & $0.001-1$ & - & $2^{[21]}$ & $0.9996^{[21]}$ \\
\hline
\end{tabular}

Moreover, the possible occurrence of fragrance allergens in 5 commercial perfumes ('Bloom Nettare di Fiori' by Gucci, 'Blue byzantine' by Rituals, 'Ladies Fleurs de l'Himalaya' by Rituals, 'Green tea scent spray' by Elizabeth Arden, 'Bright crystal' by Versace) was investigated in this study. We used the calibration curves reported in Figure 4 to quantify the fragrance allergens in all five products. The analytical results are summarized in Figure 5 and Table 3, which show that benzyl benzoate, linalool and citronellol were detected in "Bloom Nettare di Fiori"; benzyl benzoate, coumarin, citral, linalool, citronellol and limonene in "Blue byzantine"; eugenol, citral, linalool, citronellol and limonene in "Ladies Fleurs de l'Himalaya"; citral, linalool, citronellol and limonene in "Green tea scent spray"; and linalool, citronellol and limonene were detected in "Bright crystal". In order to verify that the composition of the fragrance does not affect the sensitivity of the method, a calibration via the standard addition method was performed for the perfume "Bright crystal" (Figure 6). As shown in Table 3, the calculated concentrations obtained by the standard addition method close to the values obtained by our external calibration curve. Among the perfumes we studied, "Blue byzantine" contains more types and higher concentrations of allergens than other perfumes. The compounds detected are consistent with the ingredients listed on the perfume boxes, which suggests that DBDI has the potential to detect compounds in complex fragrance products without chromatographic separation methods. We also mimicked the real fragrances by diluting "Bright crystal" in water and EtOH separately, as shown in Figure S4. There was no obvious charge competition when using our method to measure perfume in different solvents. 

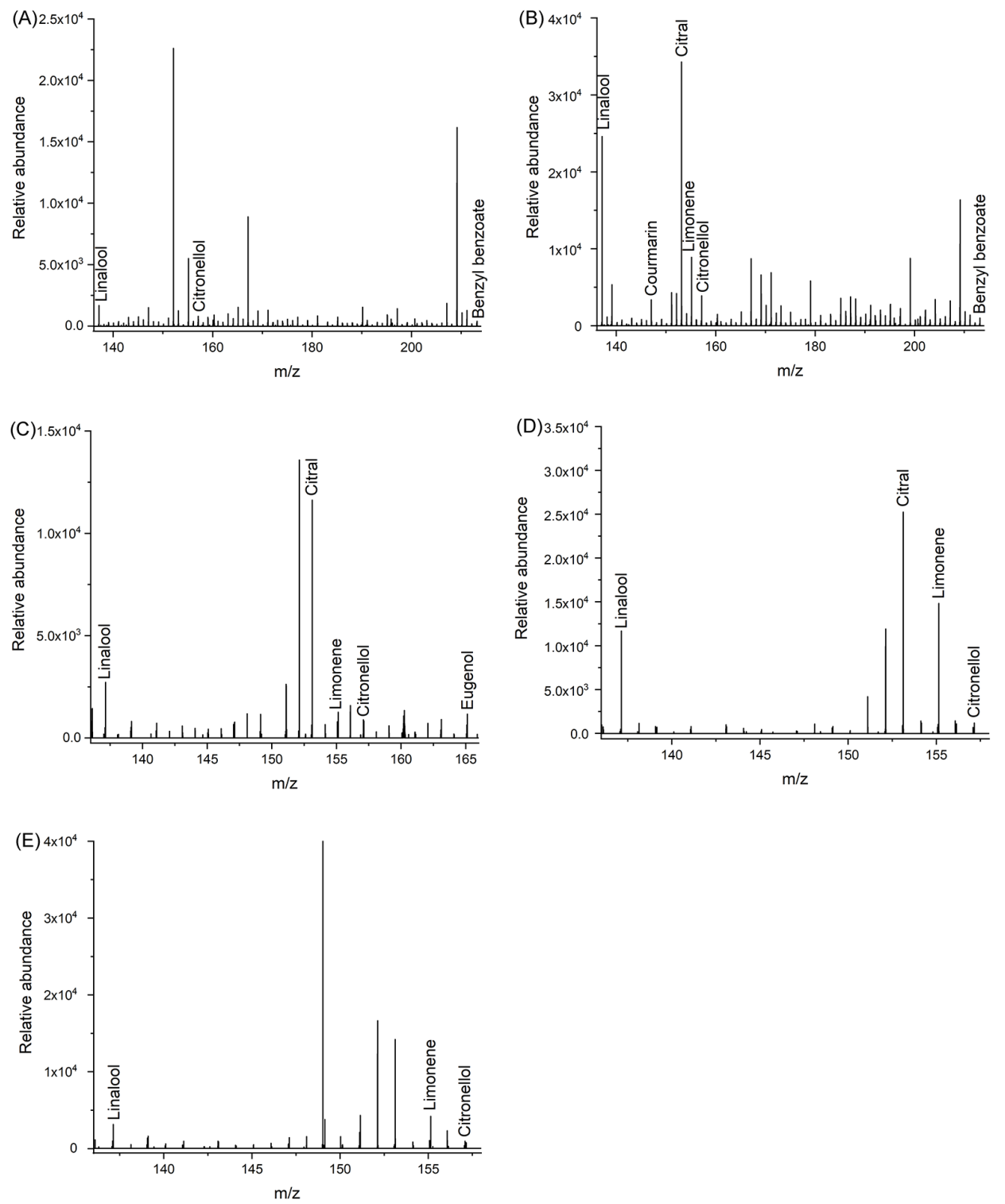

Figure 5. Mass spectra of (A) Bloom Nettare di Fiori, (B) Blue byzantine, (C) Ladies Fleurs de l'Himalaya, (D) Green tea scent spray, (E) Bright crystal.
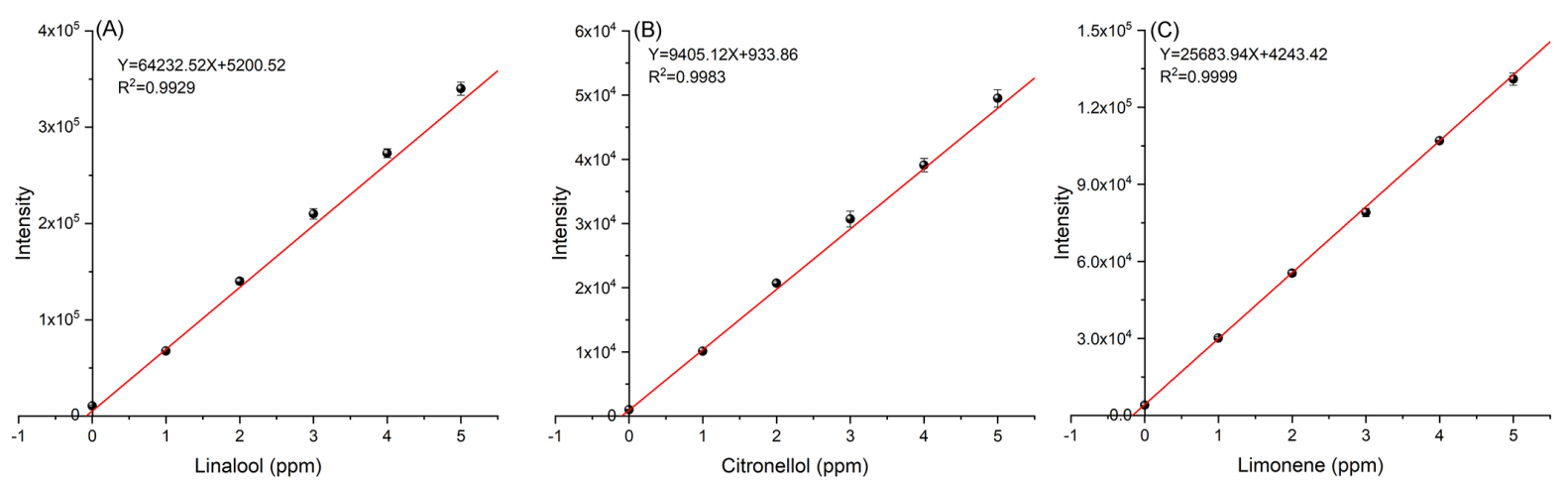

Figure 6. Quantitation via standard addition of (A) linalool, (B) citronellol, (C) limonene in "Bright crystal". 
Table 3. Quantitative analytical results for 7 fragrance allergens in 5 commercial perfumes

\begin{tabular}{|c|c|c|c|c|c|c|}
\hline Analyte & $\begin{array}{c}\text { Bloom } \\
\text { Nettare } \\
\text { di Fiori }\end{array}$ & $\begin{array}{c}\text { Blue } \\
\text { byzantine }\end{array}$ & $\begin{array}{c}\text { Ladies } \\
\text { Fleurs de } \\
\text { l'Himalaya }\end{array}$ & $\begin{array}{l}\text { Green tea } \\
\text { scent spray }\end{array}$ & Bright crystal & $\begin{array}{c}\text { Bright crystal } \\
\text { (standard } \\
\text { addition) }\end{array}$ \\
\hline & ppm & ppm & ppm & ppm & ppm & ppm \\
\hline Benzyl benzoate & 0.8 & 2.4 & - & - & - & - \\
\hline Coumarin & - & 0.2 & - & - & - & - \\
\hline Eugenol & - & - & 8.1 & - & - & - \\
\hline Citral & - & 57.1 & 19.3 & 41.9 & - & - \\
\hline Linalool & 2.4 & 37.2 & 4.1 & 17.7 & 4.3 & 4.1 \\
\hline Citronellol & 6.2 & 32.9 & 6.3 & 9.8 & 6.5 & 7.6 \\
\hline Limonene & - & 24.8 & 3.5 & 40.6 & 11.1 & 14.7 \\
\hline
\end{tabular}

\section{Conclusions}

In this work, we presented a rapid analysis of fragrance allergens by DBDI-MS. In order to verify that this method can effectively detect perfume allergens, 7 common fragrance allergens (benzyl benzoate, coumarin, eugenol, citral, linalool, citronellol, limonene) were selected for qualitative and quantitative analysis. The results showed that DBDI obtained good linear dynamic range, LODs and LOQs, irrespective of whether it was an individual sample or a mixed sample, there is no obvious matrix effects and charge competition. Without sample pretreatment, DBDI-MS successfully detected allergens in perfume samples of five different brands. In summary, DBDI has the advantages of high sensitivity, simple operation and fast analysis time. It is very suitable for the rapid analysis of trace fragrance allergens in fragrances, and could easily be used for quality control of various products in the cosmetics market.

\section{Acknowledgments and Notes}

QL thanks the China Scholarship Council (CSC) for financial support of her Ph.D. research. We also thank Dr. Sandra Martínez Jarquín for helpful comments during revision of this manuscript. The original data used in this publication are made available in a curated data 
archive at ETH Zurich (https://www.researchcollection. ethz.ch) under the DOI: 10.3929/ethzb-000454181.

\section{References}

[1] Fahlbusch K-G, Hammerschmidt F-J, Panten J, et al. Flavors and Fragrances. Ullmann's Encycl. Ind. Chem. 2003. doi:10.1002/14356007.a11_141

[2] SCCS (Scientific Committee on Consumer Safety) Opinion on fragrance allergens in cosmetic products. European Commission. 2012.

https://ec.europa.eu/health/scientific_committees/consumer_safety/docs/sccs_o_102.pdf

[3] Schnuch A, Griem P. Fragrances as allergens. Allergo J. Int. 2018;27(6):173-183. doi:10.1007/s40629-018-0075-x

[4] Reeder MJ. Allergic Contact Dermatitis to Fragrances. Dermatol. Clin. 2020;38(3):371377. doi:10.1016/j.det.2020.02.009

[5] Nilsson J, Carlberg J, Abrahamsson P, Hulthe G, Persson BA, Karlberg AT. Evaluation of ionization techniques for mass spectrometric detection of contact allergenic hydroperoxides formed by autoxidation of fragrance terpenes. Rapid Commun. Mass Spectrom. 2008;22(22):3593-3598. doi:10.1002/rcm.3770

[6] Famiglini G, Termopoli V, Palma P, Capriotti F, Cappiello A. Rapid LC-MS method for the detection of common fragrances in personal care products without sample preparation. Electrophoresis 2014;35(9):1339-1345. doi:10.1002/elps.201300462

[7] Rudbäck J, Islam N, Nilsson U, Karlberg A-T. A sensitive method for determination of allergenic fragrance terpene hydroperoxides using liquid chromatography coupled with tandem mass spectrometry. J. Sep. Sci. 2013;36(8):1370-1378.

doi:10.1002/jssc. 201200855

[8] Rudbäck J, Ramzy A, Karlberg A-T, Nilsson U. Determination of allergenic hydroperoxides in essential oils using gas chromatography with electron ionization mass spectrometry. J. Sep. Sci. 2014;37(8):982-989. doi:10.1002/jssc.201300843

[9] Barbini DA, Vanni F, Girolimetti S, Dommarco R. Development of an analytical method for the determination of the residues of four pyrethroids in meat by GC-ECD and confirmation by GC-MS. Anal. Bioanal. Chem. 2007;389(6):1791-1798. doi:10.1007/s00216-007-1440-7

[10] Portolés T, Mol JGJ, Sancho JV, Hernández F. Advantages of Atmospheric Pressure Chemical Ionization in Gas Chromatography Tandem Mass Spectrometry: Pyrethroid Insecticides as a Case Study. Anal. Chem. 2012;84(22):9802-9810. doi:10.1021/ac301699c

[11] Gyr L, Klute FD, Franzke J, Zenobi R. Characterization of a Nitrogen-Based Dielectric Barrier Discharge Ionization Source for Mass Spectrometry Reveals Factors Important for Soft Ionization. Anal. Chem. 2019;91(10):6865-6871.

doi:10.1021/acs.analchem.9b01132 
[12] Ahmed E, Xiao D, Dumlao MC, et al. Nanosecond Pulsed Dielectric Barrier Discharge Ionization Mass Spectrometry. Anal. Chem. 2020;92(6):4468-4474.

doi:10.1021/acs.analchem.9b05491

[13] Albert A, Engelhard C. Characteristics of Low-Temperature Plasma Ionization for Ambient Mass Spectrometry Compared to Electrospray Ionization and Atmospheric Pressure Chemical Ionization. Anal. Chem. 2012;84(24):10657-10664. doi:10.1021/ac302287x

[14] Wolf JC, Schaer M, Siegenthaler P, Zenobi R. Direct quantification of chemical warfare agents and related compounds at low ppt levels: comparing active capillary dielectric barrier discharge plasma ionization and secondary electrospray ionization mass spectrometry. Anal. Chem. 2015;87(1):723-729. doi:10.1021/ac5035874

[15] Nudnova MM, Zhu L, Zenobi R. Active capillary plasma source for ambient mass spectrometry. Rapid Commun. Mass Spectrom. 2012;26(12):1447-1452. doi: $10.1002 / \mathrm{rcm} .6242$

[16] Gilbert-Lopez B, Geltenpoth H, Meyer C, et al. Performance of dielectric barrier discharge ionization mass spectrometry for pesticide testing: a comparison with atmospheric pressure chemical ionization and electrospray ionization. Rapid Commun. Mass Spectrom. 2013;27(3):419-429. doi:10.1002/rcm.6469

[17] Lara-Ortega FJ, Robles-Molina J, Brandt S, et al. Use of dielectric barrier discharge ionization to minimize matrix effects and expand coverage in pesticide residue analysis by liquid chromatography-mass spectrometry. Anal. Chim. Acta. 2018;1020:76-85. doi:10.1016/j.aca.2018.02.077

[18] Gyr L, Wolf JC, Franzke J, Zenobi R. Mechanistic Understanding Leads to Increased Ionization Efficiency and Selectivity in Dielectric Barrier Discharge Ionization Mass Spectrometry: A Case Study with Perfluorinated Compounds. Anal. Chem. 2018;90(4):2725-2731. doi:10.1021/acs.analchem.7b04711

[19] Wolf JC, Schaer M, Siegenthaler P, Zenobi R. Direct quantification of chemical warfare agents and related compounds at low ppt levels: comparing active capillary dielectric barrier discharge plasma ionization and secondary electrospray ionization mass spectrometry. Anal. Chem. 2015;87(1):723-729. doi:10.1021/ac5035874

[20] Wolf JC, Gyr L, Mirabelli MF, Schaer M, Siegenthaler P, Zenobi R. A RadicalMediated Pathway for the Formation of $[\mathrm{M}+\mathrm{H}](+)$ in Dielectric Barrier Discharge Ionization. J. Am. Soc. Mass Spectrom. 2016;27(9):1468-1475. doi:10.1007/s13361-016$1420-2$

[21] Wang Z, Zhang Q, Li H, Lv Q, Wang W, Bai H. Rapid and green determination of 58 fragrance allergens in plush toys. J. Sep. Sci. 2018;41(3):657-668. doi:10.1002/jssc. 201700556

[22] Li M, Li R, Wang Z, Zhang Q, Bai H, Lv Q. Optimization of headspace for GC-MS analysis of fragrance allergens in wooden children's products using response surface methodology. Sep. Sci. plus. 2019;2(1):26-37. doi:10.1002/sscp.201800125

[23] Mazzucotelli M, Minteguiaga MA, Sgorbini B, et al. Ionic liquids as water-compatible GC stationary phases for the analysis of fragrances and essential oils: Quantitative GCMS analysis of officially-regulated allergens in perfumes. J. Chromatogr. A. 2020;1610:460567. doi:10.1016/j.chroma.2019.460567 